\title{
Corrigendum: Gamma Tocotrienol Protects Mice From Targeted Thoracic Radiation Injury
}

\author{
Vidya P. Kumar*, Sasha Stone, Shukla Biswas, Neel Sharma and Sanchita P. Ghosh * \\ Armed Forces Radiobiology Research Institute, Uniformed Services University of the Health Sciences, Bethesda, MD, \\ United States
}

Keywords: gamma tocotrienol, partial body irradiation, lung injury, SARRP, small animal radiation research platform, radiation injury to normal lungs, prophylactic treatment, thoracic irradiation

\section{A Corrigendum on}

Gamma Tocotrienol Protects Mice From Targeted Thoracic Radiation Injury

by Kumar, V. P., Stone, S., Biswas, S., Sharma, N., and Ghosh, S. P. (2020). Front. Pharmacol. 11: 587970. doi: 10.3389/fphar.2020.587970

In the original article, we neglected to include the funder "US Department of Defense Threat Reduction Agency grant H.10016_09_AR_R to SG, administered by The Henry M. Jackson Foundation for the Advancement of Military Medicine, Inc."

In the original article, we missed mentioning that we also used GT3 from American River

\section{OPEN ACCESS}

Edited and reviewed by:

Alastair George Stewart,

The University of Melbourne, Australia

*Correspondence:

Vidya P. Kumar

vidya.kumar.ctr@usuhs.edu

Sanchita P. Ghosh

sanchita.ghosh@usuhs.edu

Specialty section:

This article was submitted to Translational Pharmacology,

a section of the journal

Frontiers in Pharmacology

Received: 28 September 2021

Accepted: 21 October 2021

Published: 29 November 2021

Citation:

Kumar VP, Stone S, Biswas S,

Sharma N and Ghosh SP (2021)

Corrigendum: Gamma Tocotrienol

Protects Mice From Targeted Thoracic

Radiation Injury.

Front. Pharmacol. 12:785165.

doi: $10.3389 /$ fphar.2021.785165
Nutrition (Hadley, MA, United States). A correction has been made to Materials and Methods, GT3 Formulation:

"Pure GT3 was obtained from Yasoo Health Inc. (Johnson City, TN, United States) (Ghosh et al., 2009) and American River Nutrition (Hadley, MA, United States). GT3 and Tween $80^{\circledR}$ (final concentration 5\%) were dissolved separately in small volume of ethanol (to enable uniform mixing) and mixed together and then spin-dried under vacuum. Required volume of saline was added to the tube to achieve a final concentration of either 100 or $200 \mathrm{mg}$ GT3 in $0.1 \mathrm{ml}$."

Furthermore, we missed acknowledging Dr. Kushal Chakraborty, and missed mentioning the funding agency US Department of Defense Threat Reduction Agency grant H.10016_09_AR_R. A correction has been made to Acknowledgements:

"The authors gratefully acknowledge pathologists LTC Culp (USUHS) for histopathological evaluations of slides, the dosimetrists and SARRP operators Sungyop Kim and Dr. David A. Schauer, Kefale Wuddie and Zemenu Aschenake for animal care and manipulations, Dr. Kushal Chakraborty and Betre Legesse for technical assistance, and Anne Trias (American River Nutrition) for providing GT3. The opinions and assertions expressed herein are those of the authors and do not necessarily reflect the official policy or position of the Uniformed Services University or the Department of Defense."

The authors apologize for this error and state that this does not change the scientific conclusions of the article in any way. The original article has been updated.

Publisher's Note: All claims expressed in this article are solely those of the authors and do not necessarily represent those of their affiliated organizations, or those of the publisher, the editors and the reviewers. Any product that may be evaluated in this article, or claim that may be made by its manufacturer, is not guaranteed or endorsed by the publisher.

Copyright $\odot 2021$ Kumar, Stone, Biswas, Sharma and Ghosh. This is an open-access article distributed under the terms of the Creative Commons Attribution License (CC BY). The use, distribution or reproduction in other forums is permitted, provided the original author(s) and the copyright owner(s) are credited and that the original publication in this journal is cited, in accordance with accepted academic practice. No use, distribution or reproduction is permitted which does not comply with these terms. 